\title{
SOCIALIZATION OF BLANDED E-LEARNING LEARNING SYSTEM ON THE COLLEGE OF KINESIOLOGI
}

\author{
Sutoro' $^{1}$, Friska Sari Gracia Sinaga ${ }^{2}$, Rif'iy Qomarrullah $^{3}$ \\ Jurusan IKOR, Fakultas Ilmu Keolahragaan, Program Studi Ilmu Keolahragaan, \\ Fakultas Ilmu Keolahragaan, Universitas Cenderawasih. \\ Email: $\frac{\text { sutoro_duin@yahoo.co.id }{ }^{1}, \text { sarifriska.sinaga28@gmail.com }{ }^{2}}{\text { qomarrifqi77@ }}$ gmail.com ${ }^{3}$.
}

\begin{abstract}
Industrial Revolution 4.0 is a revolution that the currently touted by the government starting from the central government to the regional government. One of the things that can be done in improving the quality of learning, especially at the university level, is through learning that is based on learning through electronics. Electronic media that is intended is learning through blanded e learning that uses learning applications by utilizing technological advances as an effort in the implementation of the industrial revolution that is being driven in the community and in the campus environment. The purpose of the PPM (Community Devotion) program is carried out as a tri dharma task of the tertiary institution and an effort to improve the competence of students, especially students in Sport Sciences at the Faculty of Sport Science, Cenderawasih University.

The implementation of the PPM was carried out in July 2019, followed by 18 participants. The methods applied in this training are: lectures, demonstrations and practices using learning applications based on e learning.

The result is an increase in the competence of students, especially those who take kinesiology courses in understanding teaching material so that it can spread the knowledge gained to their colleagues and can then be applied to the workplace where he works later.
\end{abstract}

Keywords: Learning System, Blanded e-Learning, Kinesiology

\section{SOSIALISASI SISTEM PEMBELAJARAN BLANDED E-LEARNING PADA MATA KULIAH KINESIOLOGI}

Abstrak

Revolusi Industri 4.0 merupakan revolusi yang saat ini didengung-dengungkan oleh pemerintah mulai dari pemerintah pusat sampai pada pemerintah daerah. Salah satu hal yang dapat dilakukan dalam peningkatan kualitas pembelajaran khususnya di tingkat universitas adalah melalui pembelajaran yang berbasis pada pembelajaran melalui elektronik. Media eletronik yang dimaksudkan ialah pembelajaran melalui blanded e learning yang menggunakan aplikasi pembelajaran dengan memanfaatkan kemajuan tehnologi sebagai upaya dalam pelaksanaan revolusi industry yang sedang digerakkan di masyarakat maupun di lingkungan kampus. Adapun tujuan dari program PPM (Pengabdian pada masyarakat) yang dilakukan sebagai tugas tri dharma perguruan tinggi dan upaya untuk meningkatkan kompetensi mahasiswa khususnya mahasiswa Ilmu Keolahragaan di kalangan Fakultas Ilmu Keolahragaan Universitas Cenderawasih.

Pelaksanaan PPM ini dilaksanakan pada bulan Juli tahun 2019, diikuti 18 peserta. Adapun metode yang diterapkan dalam pelatihan ini yakni: ceramah, demonstrasi dan praktik menggunakan aplikasi pembelajaran yang berbasis pada e learning. 
Hasilnya adalah adanya peningkatan kompetensi mahasiswa khususnya yang mengambil mata kuliah kinesiology dalam memahami materi ajar sehingga dapat menyebar luaskan ilmu yang diperoleh kepada rekan sejawatnya dan selanjutnya dapat diaplikasikan ditempat kerja dimana dia bekerja nantinya.

Kata kunci: Sistem Pembelajaran, Blanded e-Learning, Kinesiologi

\section{ANALISIS SITUASI}

Dalam Era Globalisasi melalui revolusi Industri 4.0, perkembangan pendidikan di Indonesia semakin hari semakin meningkat. Terlihat jelas bila ditinjau dari semakin berkembangnya inovasi pembelajaran yang dilakukan baik ditingkat sekolah maupun universitas. Penerapan-penerapan pembelajaran yang dilakukan disesuaikan dengan kebutuhan dan tantangan perkembangan teknologi secara khusus di Indonesia. Selain itu, tugas dan pelayanan dosen sebagai pengajar dan pendidik sangat menentukan dalam peningkatan efektifitas dan kualitas pembelajaran di Universitas.

Kebutuhan dan tantangan perkembangan teknologi pada era Revolusi Industry 4.0 ini berdampak pada penerapan model-model pembelajaran yang sudah dan sedang berlangsung di pendidikan tinggi. (Ahmed at all 2009) mengungkapkan bahwa Blended e-learning merupakan pembelajaran yang bersifat penggabungan antara pembelajaran tradisional dengan pembelajaran berbasis aplikasi tehnologi seperti Web, audio visual, streaming, dll.

Seiring perkembangannya, aplikasi teknologi dengan cepat menjadi instrumen penting untuk alat pembelajaran yang berharga untuk peningkatan pengalaman secara keseluruhan, (Wang, 2009). Salah satu contoh nyata perkembangan pembelajaran di bidang IPTEK yakni sistem pembelajaran berbasis Blanded Learning. Blended Learning merupakan salah satu jawaban yang seharusnya di terapkan di kampus-kampus di Indonesia.

Blanded learning adalah metode pembelajaran yang mengintegrasikan sistem pembelajaran langsung (Life Model), belajar mandiri, dan belajar melalui online (Noer, 2010). Sejalan dengan teori diatas, (Soekartawi, Haryono dan Librero, 2002) mendefinisikan e-Learning is a generic term for all technologically supported learning using an array of teaching and learning tools as phone bridging, audio and videotapes, teleconferencing, satellite transmissions, and the more recognized web-based training or computer aided instruction also commonly referred to as online courses.

Lebih lanjut, (Martin Oliver dan Keith Trigwell 2005), mengartikan blended learning dalam 4 point besar, yakni:

1. Combining or mixing web-based technology to accomplish an educational goal;

2. Combining pedagogical approaches ('e.g. constructivism, behaviorism, cognitivism) to produce an optimal learning outcome with or without instructional technology;

3. Combining any form of instructional technology with face-to-face instructor-led training; and

4. Combining instructional technology with actual job tasks.

Seyogyanya, sistem pembelajaran online sudah diperkenalkan dan diterapkan di kampus, namun kenyataannya masih banyak dosen yang memilih sistem lama sebagai model pembelajaran yang dipakai. Khususnya di Jurusan Ilmu Keolahragaan FIK 
UNCEN, masih banyak dosen yang belum memakai dan menerapkan sistem pembelajaran berbasis online ini.

Berdasarkan tinjauan di lapangan, sebahagian besar dosen di Fakultas Ilmu Keolahragaan masih belum menerapkan system-sistem pembelajaran berbasis IPTEK. Masih banyak dosen yang menerapkan system pembelajaran demonstrasi (Life Model) sehingga menjadi fokus perhatian yang penting mengingat Pemerintah dalam hal ini baik Presiden maupun Kemenristekdikti sedang mendengungkan untuk melakukan revolusi industry 4.0 .

Salah satu bukti nyata dalam bidang pendidikan tinggi dimana revolusi industry 4.0 dapat terwujud adalah dengan menerapkan sistem-sistem pembelajaran berbasis online. Sistem pembelajaran yang dimaksudkan adalah bagaimana menciptakan suasana belajar yang kondusif bukan hanya tatap muka di kelas, namun juga dosen diharapkan dapat memanfaatkan perkembangan IPTEK sebagai media atau alat untuk menstranfer ilmu-ilmu pengetahuan kepada mahasiswa. Sehingga harapan terbesarnya adalah mahasiswa dapat menggunakan atau memanfaatkan IPTEK sebagai alat untuk memperoleh informasi terkait bidang ilmu dan menggunakannya tanpa mengalami kebingungan.

Berdasarkan masalah yang diangkat, maka tujuan dari kegiatan ini adalah:

1. Memberikan pemahaman awal (sosialisasi) kepada mahasiswa tentang sistem pembelajaran berbasis IPTEK Blended e-Learning;

2. Menerapan sistem pembelajaran berbasis IPTEk Blended e-Learning kepada mahasiswa pada mata kuliah kinesiologi.

\section{SOLUSI DAN TARGET}

Sedangkan dari segi manfaat yang akan diperoleh, maka penulis mengharapkan:

1. Agar penulis memperoleh gambaran pemahaman mahasiswa tentang sistem pembelajaran berbasis IPTEK Blended e-Learning.

2. Agar mahasiswa dapat menerapkan sistem pembelajaran berbasis IPTEK Blended e-Learning.

Untuk mencapai tujuan pengabdian ini maka langkah yang dilakukan adalah memberikan sosialisasi (pengetahuan awal) tentang sistem pembelajaran berbasis IPTEK Blended e-Learning yang meliputi mekanismenya, langkah-langkahnya, dan halhal myang dapat dilakukan saat melaksanakan proses pembelajaran berbasis IPTEK Blended e-Learning, sehingga dengan pemahaman tersebut, mahasiswa dapat menerapkan dan mahasiswa dapat berkreasi pada pembelajaran yang digunakan sehingga tujuan dalam pengabdian ini dapat terlaksana. Selanjutnya, Mahasiswa akan menerapkan system pembelajaran ini pada mata kuliah kinesiology yang sedang berlangsung sampai perkuliahan selesai.

Komunitas sasaran dalam pengabdian ini merupakan seluruh mahasiswa FIK Prodi Ilmu Keolahragaan semester 4 yang mengambil mata kuliah kinesiologi dan yang masih aktif dalam perkuliahan.

\section{METODE PELAKSANAAN}

\section{Tempat dan Waktu}


Pengabdian ini dilakukan di Program studi Ilmu Keolahragaan, Fakultas Ilmu Keolahragaan Universitas Cenderawasih, Jayapura-Papua. Pengabdian dilakukan pada bulan Juli 2019.

\section{Khalayak Sasaran}

Sasaran pada pengabdian ini ialah Mahasiswa program studi Ilmu Keolahragaan Fakultas Ilmu Keolahragaan Universitas Cenderawasih pada semester IV yang mengambil mata kuliah Kinesiologi Olahraga.

\section{Metode Pengabdian}

Dalam pelaksanaannya, plan way dapat diuraikan sebagai berikut :

1. Memberikan form berisi surat pernyataan bahwa mahasiswa bersedia untuk menjadi peserta sosialisasi sistem pembelajaran berbasis IPTEK blended e-learning.

2. Memberikan pemahaman tentang sistem pembelajaran berbasis IPTEK blended $e$ learning dimaksudkan untuk membangkitkan semangat dan kreatifitas mahasiswa pada era revolusi industry 4.0 .

3. Membagikan modul dan menjelaskan mekanisme sistem pembelajaran berbasis IPTEK blended e-learning. Penjelasan akan diberikan dalam bentuk PPT, video, dan Live Model.

4. Memberikan kesempatan untuk berdiskusi dan mengembangkan pemahaman melalui pengembangan diri seperti penyampaian argumen ataupun studi kasus sederhana berdasarkan pengamatan mahasiswa.

\section{Indikator Keberhasilan}

Untuk mencapai tujuan di atas maka langkah yang dilakukan adalah memberikan sosialisasi (pengetahuan awal) tentang sistem pembelajaran berbasis IPTEK Blended e-Learning yang meliputi mekanismenya, langkah-langkahnya, dan halhal yang dapat dilakukan saat melaksanakan proses pembelajaran berbasis IPTEK Blended e-Learning, sehingga dengan pemahaman tersebut, mahasiswa dapat menerapkan dan mahasiswa dapat berkreasi pada pembelajaran yang digunakan sehingga tujuan dalam pengabdian ini dapat terlaksana.

\section{Metode Evaluasi}

Diharapkan setelah dilakukannya kegiatan ini, yaitu dengan mensosialisasikan sistem pembelajaran berbasis IPTEK blended e-learning, diharapkan pengetahuan mahasiswa tentang sistem pembelajaran berbasis IPTEK blended e-learning akan bertambah, kreatifitas mahasiswa dalam mengelola system pembelajaran ini juga akan bertambah, mata kuliah selanjutnya yang dipelajari akan diterapkan sebagaimana baiknya; hal ini sebagai bentuk kepedulian/kesadaran akan pentingnya system pembelajaran berbasis IPTEK blended e-learning yang sesuai dengan misi pemerintah dalam melaksanakan revolusi industry 4.0

\section{HASIL DAN PEMBAHASAN}

\section{Hasil Pelaksanaan PPM}

Pengabdian masyarakat ini dilaksanakan selama 2 hari, yaitu pada hari jumat dan sabtu tanggal 19 dan 20 Juli 2019. Kegiatan berupa teori bertempat di ruangan kuliah Fakultas Ilmu Keolahragaan Universitas Cenderawasih (Uncen). Hasil dari pelaksanaan PPM adalah peserta yang mengikuti pelatihan berjumlah 18 orang, materi pelatihan yang sudah direncanakan dapat disajikan sesuai dengan 
rencana. Secara langsung peserta antusias untuk bertanya keterkaitan antara materi teori dan praktek yang dilakukan saat latihan.

\section{Pembahasan}

Pelaksanaan sosialisasi sistem pembelajaran Blanded E Learning pada mata kuliah Kinesiologi ini memiliki arti yang strategis bagi banyak pihak seperti mahasiswa, pihak tim pengabdian, dan perguruan tinggi. Dikatakan demikian karena mahasiswa mempunyai tujuan pendidikan sebagai (1) peningkatan metode pembelajaran yang terarah pada revolusi industry $4.0,2$ ) perkembangan materi pembelajaran, 3) perkembangan mental emosional, 4) perkembangan sosial dan 5) perkembangan intelektual. Tujuan akhir olahraga dan pendidikan jasmani terletak dalam peranannya sebagai wadah unik penyempurnaan watak, dan sebagai wahana untuk memiliki dan membentuk kepribadian yang kuat, watak yang baik dan sifat yang mulia; hanya orang-orang yang memiliki kebajikan moral seperti inilah yang akan menjadi warga masyarakat yang berguna.

Pada pelaksanaan PPM ternyata peserta cepat untuk menerima dan menguasai pembelajaran yang menggunakan system berbasis e learning dalam mata kuliah kinesiology ini. Hal ini disebabkan karena para peserta memilki kemampuan penyerapan pembelajaran yang bagus dan didukung dari kemampuan peserta yang menguasai tehnologi yang berbasis pada revolusi industry 4.0. Dengan modal kemampuan di atas maka peserta dengan cepat menguasai penggunaan metode pembelajaran berbasis e-learning yang dilakukan. Sehingga dari hasil kegiatan PPM ini terdapat beberapa masukan dari peserta diantaranya mengaharapkan kegiatan semacam ini lebih sering diselenggarakan, dikarenakan 1) masih banyak mahasiswa yang masih belum mengetahui dan memahami pembelajaran dengan menggunakan metode ini, 2) pembelajaran dengan metode berbasis e learning dianggap mudah dan asik untuk digunakan, 3) metode ini mengajarkan peserta untuk lebih efisien menggunakan waktu ketika tidak dapat bertatap muka dengan dosen langsung..

\section{KESIMPULAN}

1. Kesimpulan

Program PPM ini di rasa sangat penting bagi perkembangan metode pembelajaran berbasis e learning di kalangan kampus Fakultas Ilmu Keolahragaan dan juga lingkungan Pendidikan di Provinsi Papua. Dalam rangka peningkatan kualitas mahasiswa, materi yang disajikan sangat bermanfaat sekali terutama hal-hal yang praktis dapat dilakukan oleh pengajar di lapangan. Sehingga proses belajar mengajar yang seharusnya dilakukan di kelas bias dilakukan di luar jam kelas dan menjadikan proses pembelajaran semakin menyenangkan.

\section{DAFTAR PUSTAKA}

Wang, 2009, Handbook of Research on E-Learning Applications for Career and Technical Education:Technologies for Vocational Training

Hunaiyan, Ahmed, dkk, (2009), The Design Of Multimedia Blended e-Learning System : Cultural Consideraion, Journal IEEE. 
Oliver, Martin \& Trigwell, Keith, (2005), e - Learning Journal, Volume 2, Number 1 Rooney, J. E. 2003, Blended learning opportunities to enhance educational programming and meetings. Association Management, 55(5), 26-32.

Soekartawi, A. Haryono dan F. Librero, (2002), Greater Learning Opportunities Through Distance Education: Experiences in Indonesia and the Philippines. Southeast Journal of Education.

Chaeruman,Uwes A. 5 Kunci Meramu Blended Learning secara Efektif. http://www.teknologipendidikan.net/?p=499 diakses tanggal 24/02/2014 pukul 13:10 WIB

Noer, Muhammad. Blended Learning Mengubah Cara Kita Belajar Di Masa Depan.http://www.muhammadnoer.com/2010/07/blended-learning-mengubahcara kitabelajar-di-masa-depan/ diakses tanggal 24/02/2014 pukul 14:22 WIB 